\title{
'Salir del clóset' teniendo plata: un estudio sobre discriminación con hombres homosexuales de clase alta en Chile.
}

\section{'Coming out' with money: a study about discrimination with homosexual men from the upper class in Chile.}

Francisco Ulloa Osses*

\section{Resumen}

En esta investigación de tipo cualitativo se exploran las respuestas y demandas de hombres homosexuales de clase alta frente a la discriminación a causa de su orientación sexual. El hecho de enfocarse en esta fracción de clase responde a un esfuerzo por complejizar la comprensión sobre las minorías sexuales, bajo el entendido de que no sólo la discriminación de sexo-género interactúa con la clase social, sino que los capitales y recursos distribuidos desigualmente también influyen en la capacidad de los sujetos de hacer frente a la discriminación. Para llevar a cabo esta investigación se realizaron diez entrevistas semi-dirigidas de aproximadamente 90 minutos a hombres de clase alta auto declarados homosexuales, que trabajan y residen en Santiago. Los hallazgos muestran que estos sujetos se sirven de su posición de clase privilegiada para realizar particularmente operaciones conscientemente clasistas con el fin de compensar la discriminación que enfrentan.

Palabras clave: discriminación, homosexualidad, clases sociales, clases altas, compromiso político.

\begin{abstract}
In this qualitative research we explore the answers and demands set by upper-middle class men while facing discrimination over their sexual orientation. The fact of focusing on this specific social class responds to an attempt to make more complex our understanding of sexual minorities, given that not only sex-gender discrimination interacts with the social class, but also capitals and unequally distributed resources determine the capacity of subjects to face discrimination. To carry out this research ten semi-directed interviews of approximately 90 minutes were conducted to upper-middle
\end{abstract}

*Sociólogo y magíster en Ciencias Sociales de la Universidad de Chile. Investigador en Departamento de Lingüística, Universidad de Chile. Fulloao@fen.uchile.cl 
class and self-declared gay men who work and live in Santiago. The results show that these men act on their privileged class position to perform classist operations consciously to make up for the discrimination they face.

Key words: discrimination, homosexuality, social classes, upper class, political commitment.

Fecha de recepción: Abril 2019

Fecha de aprobación: Diciembre 2019

\section{Presentación}

Durante la década del 2010 se ha percibido en Chile un aumento de movilizaciones y debates acerca de la realidad que enfrentan las personas pertenecientes a las minorías sexuales, dentro de ellos los homosexuales. Podemos ubicar como un hito particular el homicidio del joven gay Daniel Zamudio en el año 2012; hecho atribuído a una motivación homofóbica y que despertó el interés de la opinión pública, especialmente de los principales afectados, sobre la frágil situación en la que viven las minorías sexuales en el país. Seguido a esto y tras seis años de tramitación, el mismo año se promulgó una Ley Antidiscriminación (Ley 20.609), que buscaba proteger a estos grupos específicamente ante actos de discriminación.

En función de estos hechos y de la promulgación de la ley, la misma organización (2013) realiza la Primera Encuesta Nacional de Diversidad Sexual y Discriminación en el año 2013. Los resultados muestran que $84,1 \%$ de la población encuestada considera que la discriminación hacia las minorías sexuales que se vive en Chile es "alta". Sumado a esto, $74,2 \%$ considera que el respeto a la diversidad sexual en el país va un por "camino regular". Otro estudio más reciente sobre actos de discriminación es el 'XVI Informe Anual de Derechos Humanos de la Diversidad Sexual y de Género en Chile' (Movilh, 2018). Sobre éste, observamos en el Gráfico 1, la evolución de los casos de discriminación perpetuados por civiles desde el año 2002 hasta el 2017. 


\section{Gráfico 1}

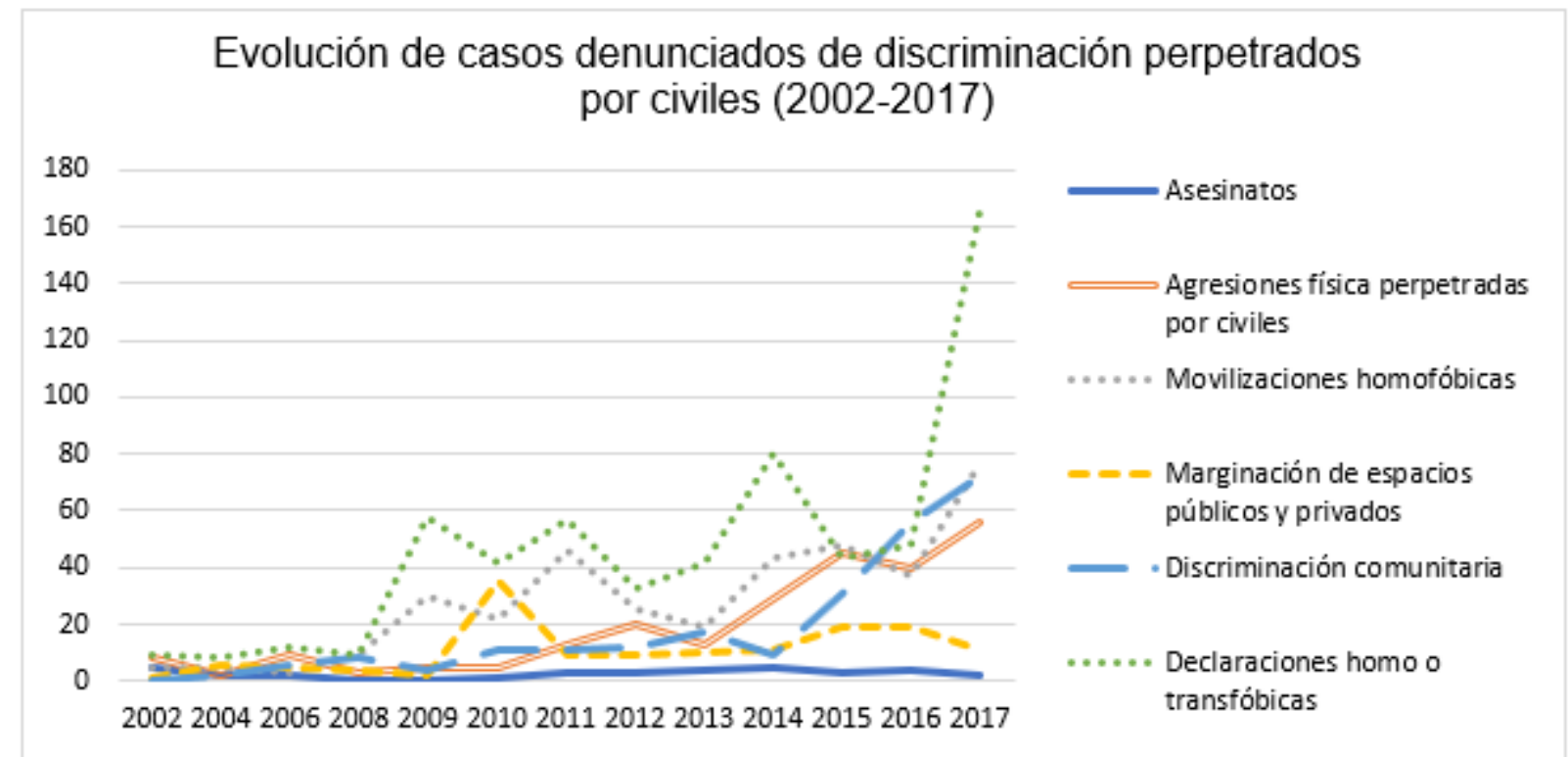

Fuente: elaboración propia a partir de datos de XVI Informe Anual de Derechos Humanos de la Diversidad Sexual y de Género en Chile' (Movilh, 2018).

Se puede destacar que desde el año 2008 hubo un ascenso en la mayoría de los tipos de discriminaciones. Aumento que sería relativamente sostenido, aunque con altas y bajas, hasta el final del período considerado. Si observamos el 2012, año en que fue promulgada la Ley Zamudio, notamos que hay una baja puntual, pero no permanente en dos tipos de discriminación: 'Movilizaciones homofóbicas' y 'Agresiones físicas perpetradas por civiles". No obstante, ambos indicadores, junto con la tendencia general, continuaron elevándose en los años posteriores. De forma similar en el Gráfico 2 se expone la evolución de casos de discriminación hacia personas por su orientación sexual o identidad de género, pero en contextos institucionales. 


\section{Gráfico 2}

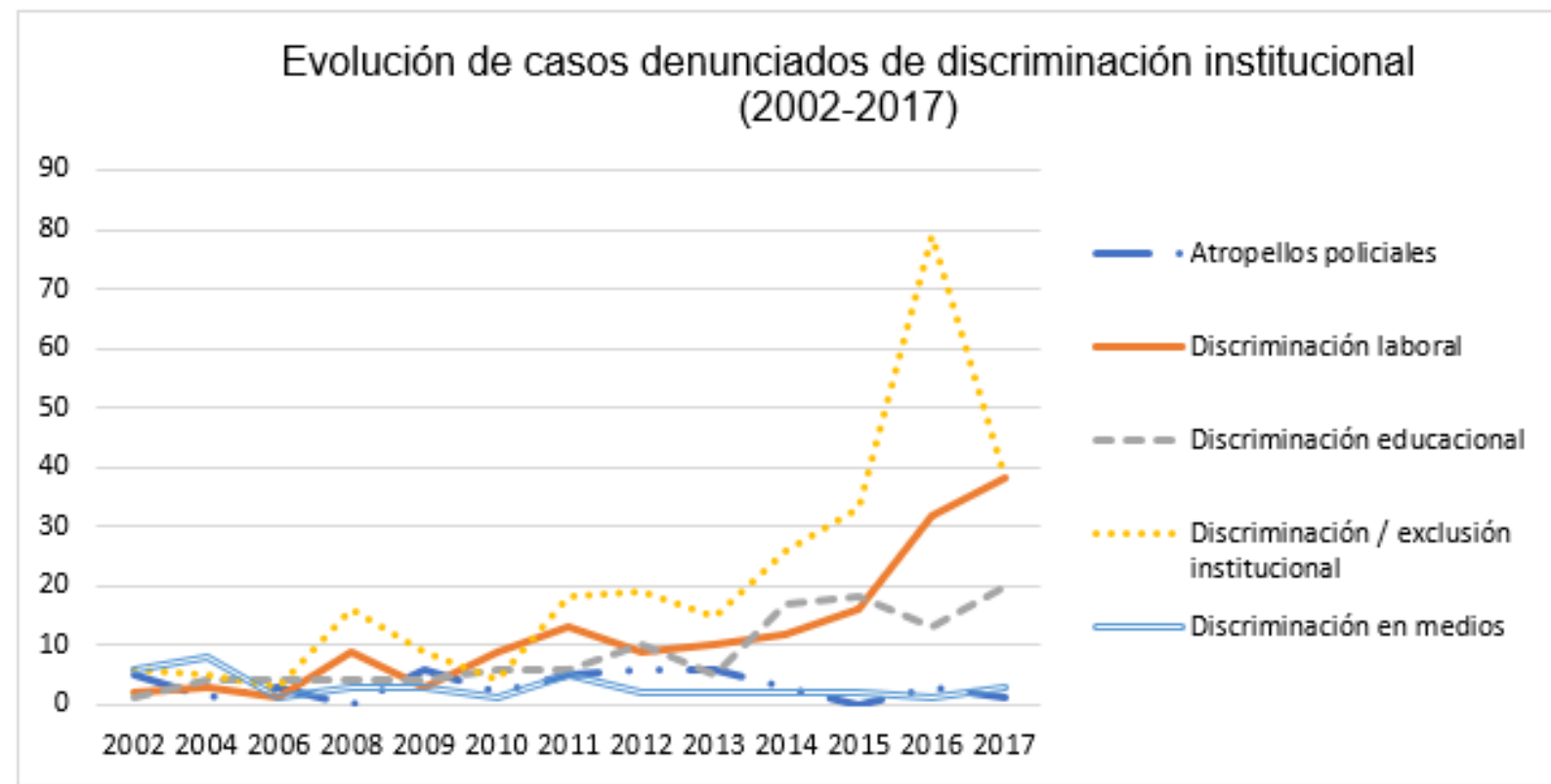

Fuente: elaboración propia a partir de datos de XVI Informe Anual de Derechos Humanos de la Diversidad Sexual y de Género en Chile' (Movilh, 2018).

A diferencia de los actos cometidos por civiles, se observa que la discriminación institucional ocurre con menor frecuencia. Sin embargo, en términos generales, estos indicadores siguen el mismo aumento progresivo en la última década que la discriminación civil. Si nos situamos en el año 2012, observamos que dos tipos de discriminaciones disminuyeron levemente: 'Discriminación/exclusión institucional' y 'Discriminación educacional'. No obstante, ambos indicadores aumentaron con fuerza en el año posterior. Desde el mismo año 2012, los dos tipos que disminuyeron hasta el año 2017 son, de manera más clara, los 'Atropellos policiales', y de manera relativa, la 'Discriminación en medios'.

Cabe destacar que, si bien ha existido un avance e interés por abordar las temáticas de discriminación hacia la diversidad sexual y de género durante estos últimos años, los avances en esta materia, como proyectos de ley en trámite o aprobados, estudios o discursos, se orientan principalmente hacia la igualdad de derechos civiles. Sin embargo, estos "avances" no se harían cargo efectivamente de la cara más violenta de las diversidades ni de las grandes diferencias internas que determinan la forma en que cada sujeto/a experimenta la pertenencia a alguno de estos grupos minoritarios. En efecto, se considera que al menos se estarían olvidando dos elementos fundamentales respecto a las minorías sexuales y específicamente relativas a la homosexualidad en el tratamiento político y social que se le ha dado en el país. El primero hace referencia a que el concepto "homosexual" históricamente desde su génesis y despliegue desde fines 
del siglo XIX, no constituyó a un solo sujeto homosexual, sino que, al contrario, internamente dentro de este grupo habrían existido y hasta el día de hoy, importantes diferencias tanto de clase como de género, etnia, performance, etc. Distan diametralmente, por ejemplo, las condiciones de llevar la sexualidad de un hombre activo sexualmente, a uno pasivo, masculino, femenino, "oso", "twink"1, "hombre weviado" y hasta los más recientemente apelados HSH (Hombres que tienen Sexo con Hombres). Del mismo modo, para finales del siglo pasado, las diferenciaciones que configuraron la "loca" y el "homosexual masculinizado" no sólo representan variantes de una misma orientación sexual, sino que corresponden a distintas posiciones de clase que conllevan distintas ideologías, prácticas y formas de ejercer poder y ser sujetos de dominación o discriminación.

En la misma línea, el segundo elemento no considerado tiene que ver con el contexto social chileno marcado por una hibridación cultural entre lo tradicional y lo moderno. Es decir, instituciones históricas conservadoras e influencia modernizadora de apertura hacia una diversidad de identidades, altos niveles de desigualdad y exclusión, y un consumo de tipo imitativo para casi todos los grupos sociales (CEPAL, 1992) que sería fundamental a la hora de adquirir estatus social en el proceso de presentación del self.

Particularmente, el proceso de la cuestionada normalización de los gays ocurriría de la mano de transformaciones de la sociabilidad homosexual a partir de los años 70'. Década caracterizada por la institucionalización de la vida gay y la masculinización de la imagen del varón homosexual. En efecto, se constituiría una imagen de hombre gay normalizada, que en la medida que se visibiliza, deja afuera todos los elementos que otrora la asociaban a lo anormal o a lo indeseable: la imagen del hombre feminizado como "la loca", lo travesti y la prostitución masculina, el SIDA, la marginalidad, la promiscuidad y elementos folclóricos; en oposición a la imagen del gay joven, moderno, viril, empresario y solvente económicamente (de Baére, Zanello \& Romero, 2015).

Para la presente investigación, se parte de la premisa que la constitución de estos sujetos, y especialmente de los/las más excluidos/as, se daría en gran medida a través del consumo y la normalización de las imágenes de las identidades. Para esto en el caso de Chile, nos apoyamos en los resultados de la Encuesta Casen (2015), representativa a nivel nacional, que muestran que los(as) bisexuales y homosexuales perciben un ingreso significativamente mayor al de personas heterosexuales. Confusamente, pues no se sabe, por una parte, cuál es la direccionalidad de esta correlación. Esto es, si las personas homosexuales y bisexuales perciben mayores ingresos a causa de su orientación sexual o si la homosexualidad y bisexualidad se concentra entre las personas con mayores ingresos. Es decir, en términos coloquiales, si se tiene plata por ser gay, si se puede ser gay porque se tiene plata o si uno/a puede declararse gay por tener plata. Por otra parte, es probable también que esta manifiesta

\footnotetext{
1 Oso y Twink son un par contrario. El primero son hombres grandes corporalmente y peludos. El
} segundo es un joven, valga la redundancia, juvenil y de aspecto limpio. 
correlación se deba a condiciones metodológicas de realización de la encuesta. Independiente de cuál es la lectura de estos resultados o de la validez de las condiciones metodológicas, las personas homosexuales y bisexuales aparecen representadas percibiendo significativamente un mayor ingreso que las personas heterosexuales (la encuesta en otro ítem indica la misma correlación, pero con la variable "años de escolaridad").

\section{Gráfico 3}

\section{Ingreso promedio del trabajo en personas de 18 años o más ocupadas, por orientación sexual (2015)}

(Pesos de noviembre de 2015, personas de 18 años o más ocupadas)

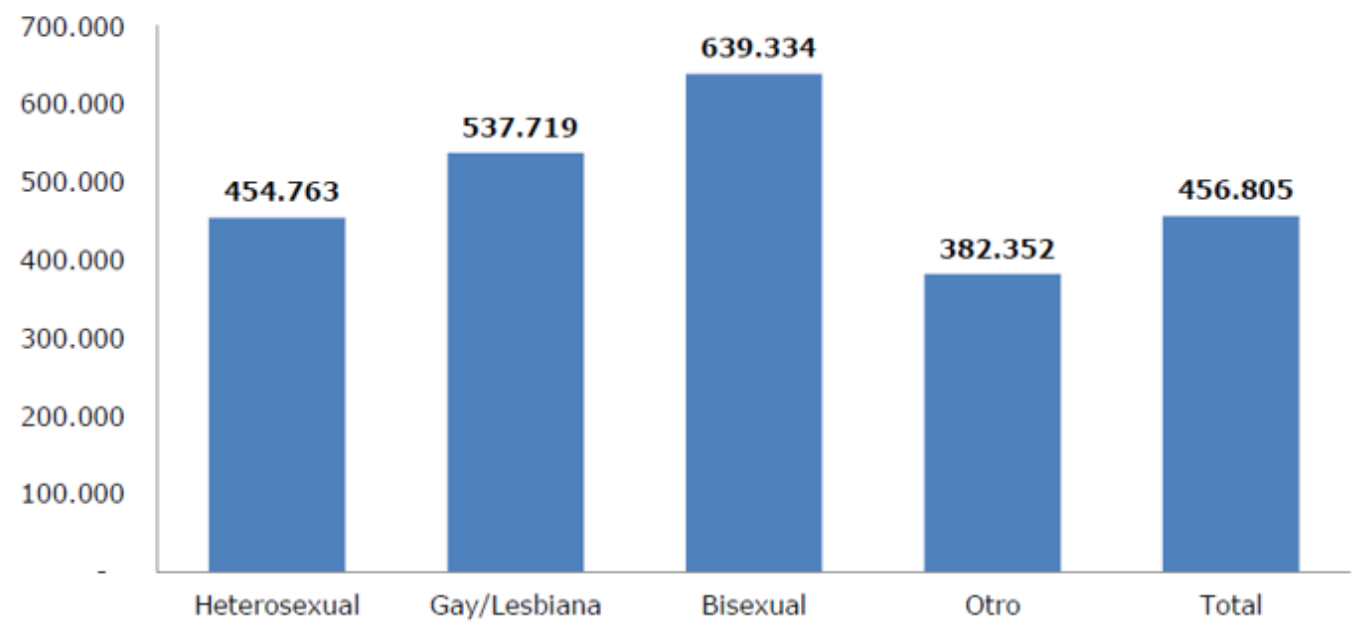

Fuente: Ministerio de Desarrollo Social, Encuesta Casen 2015

Nota: Al 95\% de confianza, las diferencias por ingreso promedio de la ocupación principal son estadísticamente significativas, excepto entre la categoría gay/lesbiana y bisexual

El hecho que el mercado sea uno de los principales medios visibilizadores del hombre gay acarrea una serie de problemas. El más directo es que existiría una hegemonía de la identidad homosexual ("gays de clase alta") implicando que quien desee representar socialmente esta orientación sexual, debe contar como condición con una serie de capitales para ejercer y demostrar en su entorno. De ello se deriva que, por la lógica de exclusión del capital, una gran mayoría de los sujetos homosexuales quedaría fuera de este tipo ideal. Un segundo problema es que este modelo, al ser mediado por el mercado, respondería a la ideología predominante, a saber, del capitalismo neoliberal, limitando cualquier opción disruptiva del orden actual que pueda 
resultar de esta orientación sexual: capitalismo rosa². Por último, la estratificación propia de nuestras sociedades dentro del mundo gay da origen a sujetos que poseen más y menos recursos y capitales de todo tipo para abordar su situación de discriminación en la medida en que unos encarnan el estereotipo actualmente más difundido y previamente aceptado de hombre homosexual de clase alta y los otros quedan simplemente fuera del espacio de representación del hombre homosexual o les queda encarnar a la histórica loca.

En base a este panorama, podemos distinguir al menos dos tipos de discriminación específica que ocurren en torno a los homosexuales. La primera es la discriminación a causa de la orientación sexual-identidad de género y la segunda, discriminación que se produciría dentro del 'mundo gay' principalmente en función de la tenencia o no de capitales que acercaría o alejaría a los sujetos de este modelo ideal previamente aceptado.

En vista de lo anterior, para efectos de este estudio, el foco estará puesto en las respuestas, actitudes y recursos que tienen estos hombres homosexuales de clase alta a la hora de enfrentar pruebas de discriminación en función de su orientación sexualidentidad de género. El hecho de enfocarse en los sectores altos se debe a que es principalmente aquí donde se define el espacio social y simbólico dentro del 'mundo gay' y no en las fronteras entre las clases. Asimismo, se optó por tomar a la clase alta y profundizar de forma empírica en cómo operan los sujetos dentro de ella. Se espera aportar con esto a la comprensión de la clase dominante a través del discurso del sujeto que es parte de ella pero que, por sus atributos, también la tensiona. De esta forma, el presente estudio espera ser una contribución a las líneas recientes de investigación, donde podemos destacar a Madrid (2016), que buscan profundizar nuestra comprensión de la consubstancialidad entre sexualidades y clases sociales en Chile.

Se analizará sobre la base de sus experiencias personales qué creen estos sujetos que motiva a otros sujetos a discriminarlos por su orientación sexual, con el fin de trazar en qué nivel de profundidad de las estructuras sociales se ubican los prejuicios que guían al acto de discriminación. También examinaremos si las respuestas a estas pruebas de discriminación abordan o no el mismo nivel de profundidad de los motivos que conducen el acto discriminatorio.

Proponemos entender los actos de discriminación a modo de pruebas en el sentido expuesto por Martuccelli, como "desafíos históricos, socialmente producidos, culturalmente representados, desigualmente distribuidos" (Araujo y Martuccelli, 2010: 83) que los individuos están obligados a enfrentar en el transcurso de su vida cotidiana y a través de los cuales estos se individualizan. El aporte de integrar esta perspectiva es que a través de la caracterización de un conjunto estandarizado de pruebas

\footnotetext{
2 El capitalismo rosa supone la integración de los sujetos "homonormados" a la sociedad mediante el mercado capitalista de consumo. El juego se encuentra en los espacios de representación que las empresas abren para estos sujetos a cambio de la fidelización de nuevos nichos de mercado y del carácter amigable que adquieren sus imágenes corporativas.
} 
significativas que debe enfrentar un individuo, en este caso un 'hombre homosexual de clase alta', es posible a su vez caracterizar una sociedad (Araujo et al., 2010) en los valores que ésta impone estructural y desigualmente a las y los individuos. Así, este discurso producto de la prueba de discriminación también nos permite esbozar un retrato de la sociedad, en este caso, en relación con cómo es percibida frente a los procesos de visibilización/discriminación que viven estos sujetos.

\section{La discriminación: una concepción ampliada}

La discriminación puede definirse como un "tratamiento desigual, injusto, parcial o prejuiciado, sobre la base de la pertenencia a grupos o categorías particulares de personas que han sido socialmente estigmatizadas" (ONUSIDA, 2012: 7). Feagin \& Eckberg (1980) ofrecen una comprensión ampliada de la discriminación distinguiendo distintas dimensiones de ésta: la motivación (a), la acción discriminatoria (b), los efectos (c), la relación entre motivación y acción (d), la relación entre acción y efectos (e), el contexto organizacional inmediato (f) y el contexto societal amplio (g) (ver Diagrama 1). En principio, deteniéndonos en los motivos, los mismos autores (Feagin et al., 1980) distinguen tres tipos de motivaciones que están en la base de actos discriminatorios: los motivados por prejuicios, los motivados por la conformidad y los motivados por la ganancia de algún beneficio. En el primer caso, los prejuicios actúan como un complejo de creencias "que están detrás del comportamiento discriminatorio por parte del grupo mayoritario" (Myrdal, 1964: 52).

Diagrama1. Las dimensiones de la discriminación

Immediate Organizational

Context (f)

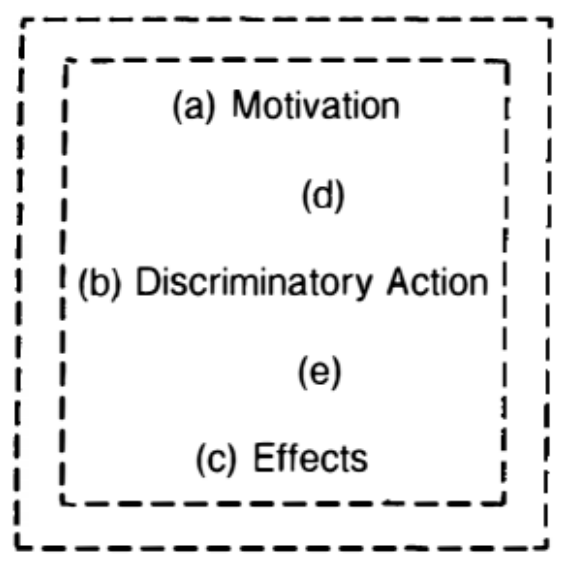

Larger Societal Context (g)

Fuente: extraído de Feagin \& Eckberg, 1980: 2. 
En cuanto a los tipos de actos discriminatorios, Feagin et al. (1980) identifican cuatro según la combinación entre el grado de intencionalidad (entera o parcial) y si están incrustados en organizaciones de mayor escala. Distinguen, de esta manera la 'discriminación aislada', la 'discriminación de grupo pequeño', la 'discriminación institucionalmente directa' y 'discriminación institucional indirecta'. Veremos más adelante en el análisis, otras funciones más indirectas que puede cumplir el acto de discriminación.

En este caso específico de discriminación hacia personas homosexuales, se pueden identificar al menos tres tipos de actitudes personales, que son parte de la vida cotidiana de gays y lesbianas, que están asociadas a repertorios sociales de acción (Lamont et al. 2013) y que son producidos a modo de contexto, respondiendo al aparataje ideológico dominante (de Baére et al., 2015, Arrivo, s.f.): la homofobia, el heterosexismo y los prejuicios sexuales. La homofobia puede comprenderse como el pavor de cualquier persona de estar cerca o en contacto con homosexuales, especialmente en el caso de los hombres, que tienden a tomar una mayor distancia social con los gays dado que esto aumenta las "probabilidades de que la cercanía con ellos sea interpretada como similitud categorial y con ello se expongan al castigo social que dicha semejanza percibida podría acarrear" (Barrientos \& Cárdenas, 2013:5). Igualmente, la homofobia puede expresarse en el desprecio de los/las homosexuales con ellos(as) mismos (Weinberg, 1972), es decir, una suerte de introyección de las representaciones sociales estigmatizantes y prejuiciosas: homofobia internalizada ${ }^{3}$.El heterosexismo es usado como un "término análogo al sexismo y racismo, describiendo un sistema ideológico que niega, denigra, y estigmatiza cualquier forma no heterosexual, identidad, relación o comunidad" (Drydakis, 2009: 364). Por último, los prejuicios sexuales, término con el que se sugiere reemplazar el concepto de homofobia, refiere a cualquier actitud negativa basada en la orientación sexual, ya sea a personas heterosexuales, bisexuales u homosexuales (Herek, 2000).

Respecto a otras instituciones contextuales que sirven de base a las inequidades entre los géneros y entre las distintas orientaciones sexuales, se encuentra el androcentrismo, que Nancy Fraser entiende como "un patrón institucionalizado de valor cultural que privilegia los rasgos asociados con la masculinidad, al tiempo que devalúa todo lo codificado como "femenino" (Fraser, 2008:29). El androcentrismo en América Latina propicia la extensión del machismo y el marianismo, que en su conjunto y por separado contribuyen al sometimiento y discriminación hacia las mujeres, hacia lo femenino y, por ende, refuerza la homofobia masculina en tanto la homosexualidad en hombres expresaría rasgos y conductas asociadas socioculturalmente con lo femenino (Barrientos et al., 2013). De hecho, estudios muestran que hombres gays y bisexuales que se consideran como afeminados tienen mayores niveles de angustia psíquica y

${ }^{3}$ Existe una imprecisión relativa al uso de este término, pues la homofobia no es entendida comúnmente en sí como una fobia, sino como una hostilidad hacia homosexuales (Barrientos et al., 2013). 
reportan más frecuentemente experiencias negativas relativas a su orientación sexual, en comparación a hombres gays y bisexuales que no se autoidentifican como afeminados (Sandfort, Melendez \& Díaz, 2007).

Considerar a gays y lesbianas como representantes de una sexualidad despreciable somete a estas personas a formas de vergüenza y agresiones, exclusión de derechos y privilegios del matrimonio, a la parentalidad, limita los derechos de expresión y asociación, genera hostilidad y menosprecio en la vida cotidiana y niega los derechos plenos y protecciones equiparables de los ciudadanos (Fraser, 2008). Por último, los prejuicios materializados en actos discriminatorios también tienen un fuerte impacto en su salud y bienestar (Barrientos et al., 2013). Sobre esto, de los pocos estudios que existen en Chile, Barrientos, Cárdenas \& Delgado (2014) muestran que los gays chilenos presentan menores niveles de felicidad en comparación con la población general.

\section{Panorama nacional de discriminación hacia personas homosexuales}

La Encuesta Nacional UDP 2005-2015 (2015), que explora en las valoraciones respecto a distintas dimensiones concernientes a la diversidad sexual, ofrece otra perspectiva interesante para entender qué es lo que subyace a la discriminación hacia homosexuales. Los resultados de la encuesta muestran que durante los años 20102014, efectivamente ha habido un aumento en la aceptación a la homosexualidad como una orientación válida como cualquier otra y a aspectos relativos al matrimonio y la adopción. Junto a esto, en consecuencia, habría existido en el país una disminución del rechazo en los mismos ítems. Sin embargo, sí preocupa que aún un alto porcentaje de personas se encuentren en contra de aspectos relativos a la homosexualidad y por lo tanto se dificulta su plena aceptación social: 
Revista Punto Género № 12. Diciembre de 2019

ISSN 0719-0417 / 73 - 100

Gráfico4

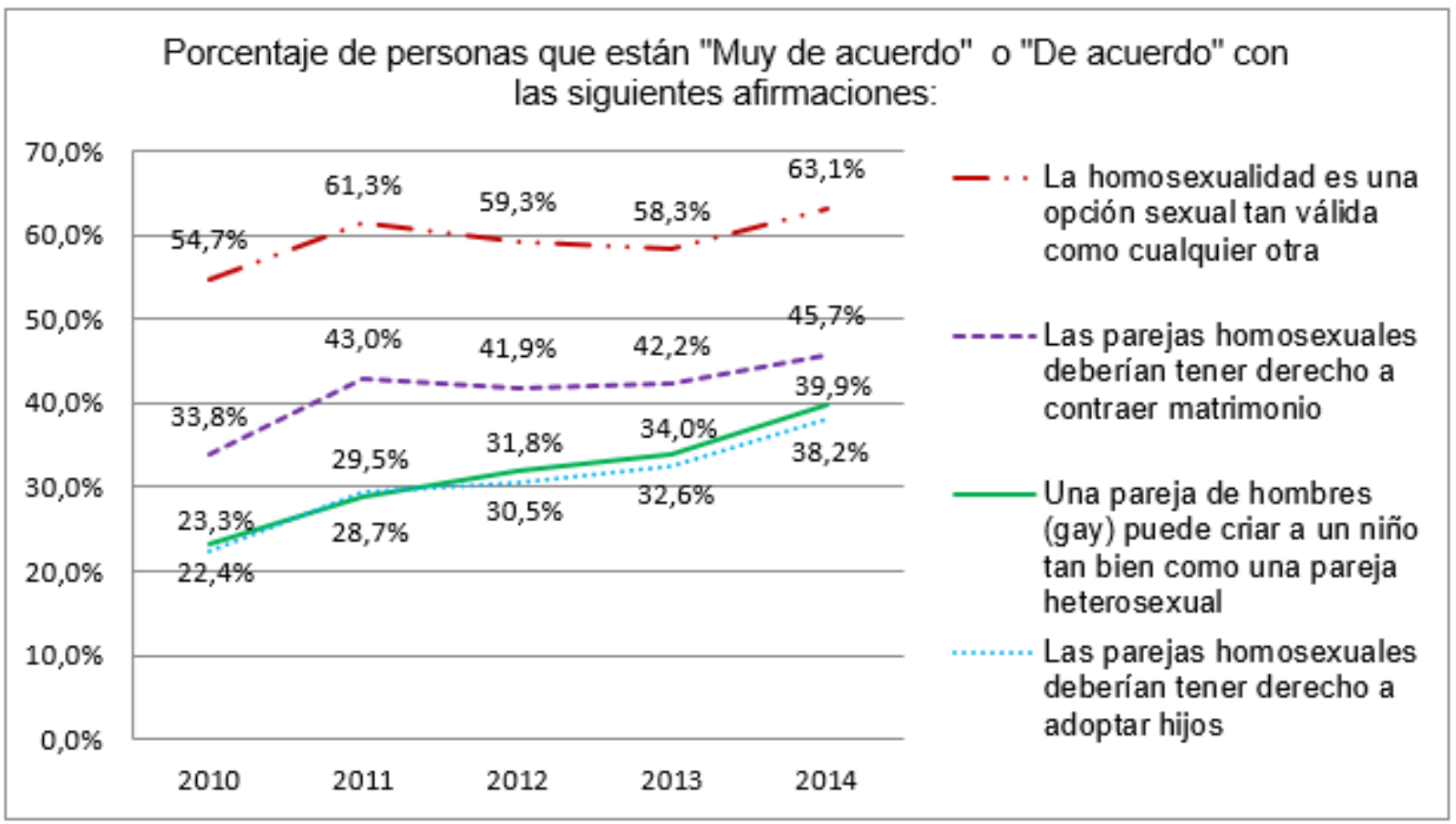

Fuente: elaboración propia a partir del resultado de las preguntas V173, V174, V176 y V177 de la Encuesta Nacional UDP, 2005-2015 (2015). 


\section{Gráfico 5}

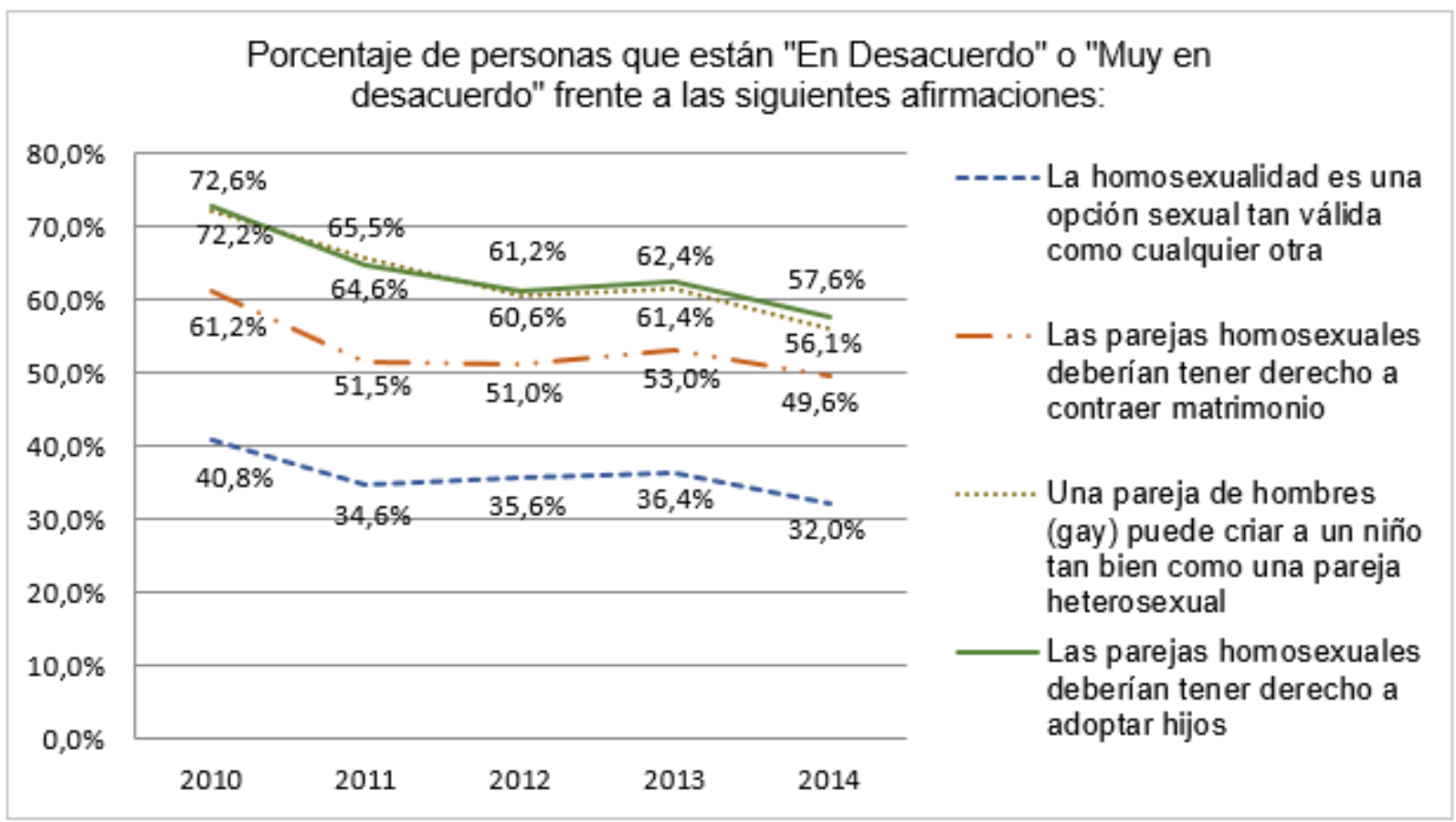

Fuente: elaboración propia a partir del resultado de las preguntas V173, V174, V176 y V177 de la Encuesta Nacional UDP, 2005-2015 (2015).

Llama la atención de los gráficos anteriores que, si bien efectivamente ha habido un aumento en la aceptación de los distintos puntos concernientes a la homosexualidad y una progresiva disminución de las opiniones que la rechazan, sí puede establecerse que los ámbitos en que la aceptación es mayor y el rechazo es menor son aquellos de carácter más privado y distante como la aceptación de la orientación homosexual como legítima y el derecho a contraer matrimonio. Sin embargo, los ítems que muestran menor aceptación y mayor rechazo son los relativos a la homo-parentalidad. Esto da cuenta de los prejuicios que subyacen en nuestro país respecto a los homosexuales como incompatibles con las imágenes de familia o como ejemplos a seguir. Es decir, que en el año 2014 un 63,1\% de la población encuestada se manifieste "De acuerdo" o "Muy de acuerdo" frente a la homosexualidad como una opción sexual tan válida como cualquier otra y que al mismo tiempo, un $57,6 \%$ de la misma muestra se encuentre "En Desacuerdo" o "Muy en desacuerdo" frente a que las parejas homosexuales deberían tener derecho a adoptar hijos, devela que aparte de que existe una mayoría de la población que tiene prejuicios negativos en contra de la homosexualidad, hay al menos un $20,7 \%$ de la población que contradictoriamente sí considera que la homosexualidad es tan válida como cualquier orientación sexual, pero que al mismo tiempo no es tan válida como un modelo de parentalidad. Esto se condice con falacias que son posibles escuchar en el discurso cotidiano de personas, como, por ejemplo: "yo no soy homofóbico, pero que no se den besos al frente mío". 


\section{Lidiando con la discriminación}

Analíticamente, en cuanto a las respuestas frente a la discriminación, se propone reconocer a grandes rasgos entre lo que se dice, cómo se dice (modalidad de respuesta) y si es que existe una diferencia entre la respuesta dada y la respuesta ideal que el sujeto podría haber dado en otra situación particular. Sobre lo que se dice, la importancia recae en comprender los recursos que son movilizados para enfrentar los procesos de discriminación y estigmatización, pues bajo la ideología neoliberal, ésta actuaría como un contexto que favorece respuestas de tipo individualista (Lamont et al., 2013), que no aportarían a un cambio de percepción de los prejuicios que están a la base de la discriminación, ni a una unidad y cohesión entre el grupo dominado.

Luego, se distinguen principalmente dos modalidades de respuesta: evadir el acto discriminatorio o afrontarlo. Sin embargo, antes de desarrollar cada una de estas salidas, cabe recalcar que la discriminación subyace en las representaciones sociales que conforman los espacios, por lo que no es necesario un acto discriminatorio manifiesto para encontrarse en una situación de discriminación. Ejemplo de estos son los chistes sexistas y homofóbicos comunes y corrientes en presencia de personas de las que no se sabe su orientación (homo)sexual.

De esta manera, las opciones de afrontar o evitar el proceso de discriminación se juegan también en si es que el sujeto denigrado quiere asumir o no su condición de homosexual y acarrear en el instante con los costos asociados a dicha transgresión. Es decir, si opta por romper con las expectativas de las personas que presumen la heterosexualidad sobre el resto. Las consecuencias de esto implican que en el caso de que el sujeto decida afrontar la discriminación, será aquél quien, paradójicamente, inicie manifiestamente el proceso de discriminación desde el lado del discriminado o el estigmatizado. Esto puede comprenderse como un acto de compromiso político ${ }^{4}$ y demanda de reconocimiento, ya sea reclamando inclusión o educando o reformando a los sujetos discriminadores. Al contrario, la evasión puede derivar en ignorar el acto o alejarse y eventualmente cortar el contacto ${ }^{5}$. Esto contribuye y refuerza la exclusión de los grupos minoritarios. Sin embargo, las respuestas sean individuales o grupales, confrontacionales o evasivas, se evalúan según lo que está en juego en cada momento específico de discriminación: cantidad de personas del grupo dominante y del grupo subordinado, grado de institucionalidad del contexto, cercanía entre los interactuantes, compromiso político y expectativas de conseguir algo específico.

${ }^{4}$ En el sentido de political commitment/engagement politique.

${ }^{5}$ Estas categorías de evasión y confrontación fueron sacadas del estudio de Lamont et al. (2013). 


\section{Estrategia metodológica}

Para responder a las interrogantes planteadas en esta investigación, se realizaron entrevistas semi-dirigidas de aproximadamente 90 minutos a 10 hombres, seleccionados mediante un muestreo de bola de nieve, de entre 26 y 62 años 6 auto-declarados como homosexuales (no necesariamente en todos los espacios), que actualmente trabajan en Santiago y que pertenecen a las clases altas del país.

De manera operativa, se está entendiendo como clase alta a sujetos que posean educación superior universitaria completa en instituciones prestigiosas y que habiten en las comunas o sectores de más altos ingresos de Santiago. Sin embargo, el principal criterio de muestreo es que los sujetos correspondan o se acerquen al 'modelo' caracterizado anteriormente, ya sea yendo a los lugares de homosociabilidad destinados a este 'perfil alto' o realizando prácticas que denotan una marca de clase o valor signo de los más comunes, en términos de Baudrillard (1974), como hacer deportes de nieve o tener vacaciones en el extranjero fuera de América Latina. En suma, se optó por una suerte de materialización de la dimensión ideológica de lo que es pertenecer a una clase, en términos de estatus y prestigio.

En términos socioeconómicos, estos grupos corresponden a lo comúnmente conocido como el grupo "ABC1", es decir, personas de sectores altos y medios altos. Específicamente para efectos de la muestra de esta investigación, se trabajó con los grupos A $(0,2 \%)$, B1 (0,6\%), B2 (1,9\%) y C1a (3,9\%); o sea, con el $7,1 \%$ de la población chilena con mayores ingresos y más altos y mejores niveles de educación, salud, condiciones laborales, satisfacción positiva con su vida, posesión de bienes tecnológicos y tamaño de vivienda (CASEN, 2013; Allan, 2015). Las personas dentro de estos grupos ocupacionalmente hablando son capitalistas, ejecutivos/as, profesionales y técnicos/as y pequeña burguesía, según la clasificación de Torche y Wormald (2004).

En función del objeto de estudio, se realizó un análisis orientado principalmente por el análisis de contenido (Andréu, 2001), tomando consideraciones del análisis crítico del discurso, siguiendo la perspectiva de Reisigl y Wodak (2008) y aspectos del estudio de las representaciones sociales y el análisis estructural del discurso propuesto por Martinic (2006). Se puso especial énfasis en la crítica al texto o discurso-inmanente, con el fin de descubrir inconsistencias, auto-contradicciones, paradojas y dilemas en lo interno del texto o en las estructuras internas del discurso. La codificación de las entrevistas fue mixta.

\footnotetext{
${ }^{6} \mathrm{Si}$ bien no se profundiza en la discusión a lo largo del texto sobre la diferencia de edad de los entrevistados, es necesario tener presente en la lectura de los hallazgos el contexto que afecta la manera en que cada sujeto enfrenta la asunción y performance de su orientación sexual. Sólo como dato orientador, según el estudio 'La sexualidad de los chilenos 2017' de la agencia GFK Adimark, las personas que prefieren tener relaciones con personas del mismo sexo representan un $9 \%$ de la generación "Millenial" (15-35 años), $10 \%$ de la "Generación X" (36-50) y 6\% de los/las "Baby Boomers" (51+). En general, 9\% de la población prefiere tener relaciones con personas de su mismo sexo y $1 \%$ con ambos sexos.
} 


\section{Hallazgos y análisis}

\section{¿Qué se percibe como la causa de la discriminación homosexual?}

En primer lugar, emergió en el discurso de los entrevistados la ignorancia o la falta de educación como lo que permite la reproducción de los prejuicios. En varias de las historias de los entrevistados, relatan en algún momento la falta de información sobre que 'es normal ser una persona gay'. Esto opera tanto para los hombres gays en su proceso de reconocer y asumir su propia orientación sexual, como para el resto enfrentar una orientación sexual distinta a la 'normal'. Yván (ingeniero comercial, 26 años) entiende al respecto:

"Yo creo que ser una persona homofóbica es ser ignorante. Al igual que una persona xenofóbica, al igual que una persona racista." (Yván, 26 años, ingeniero comercial)

No obstante, la ignorancia en sí misma no motiva a la acción discriminatoria, puesto que la ignorancia es el desconocimiento sobre algo, mientras que la discriminación es un acto fundado sobre un prejuicio ya consolidado. Cuando cuestiono a Yván sobre esto, concluye que la ignorancia es también el espacio de las representaciones prejuiciosas y dañinas sobre los homosexuales: "¿qué es lo que molesta? Es que la persona es ignorante y entonces no puede ver más allá de esos prejuicios. Para mí, prejuicio es que una persona homosexual es una persona travesti. Ése era un prejuicio mío. $Y$ era porque yo nunca había conocido a una persona homosexual fuera de lo que a mí me metían en la cabeza".

Desde su experiencia, los entrevistados dan cuenta cómo la heteronorma es el espacio para que los prejuicios proliferen. Vicente (29 años, ingeniero comercial) comenta cómo vive esto en su lugar de trabajo, una agencia boutique de publicidad, en relación con sus compañeros y jefe:

"O sea, eso es lo incómodo o en la pega igual están hablando todos, ah la mina rica y yo como... (silencio) [...]Todos los días, todos los ejemplos son: hagamos una campaña con... porque una campaña no puede ser con la mina fea del curso, tiene que ser con la mina rica, la que todos quieren agarrarse [besar], pero nadie puede." (Vicente, 29 años, ingeniero comercial)

Vicente declara que esto no es para nada un problema en el día a día, a pesar de ejemplificar también momentos en que lo han perseguido morbosamente para saber sobre su sexualidad, o que ha presenciado denigración hacia personas homosexuales por parte de jefes que no conocen su propia orientación sexual.

Silvain (30 años, diseñador) comenta claramente una ocasión en que se enfrentó con miedo a ser reprobado por la heterosexualidad como régimen político, es decir, 
cuestionar la heteronorma como un conjunto de reglas incorporadas difícilmente quebrantables:

"Era la despedida de una amiga que es gringa y nosotros éramos los únicos gays e igual fue raro sentirse como minoría como tan directamente ¿cachai? Porque normalmente en las fiestas gay, tú estay y chao, tú estay no más. Como que no te pegai' el cacho (no te das cuenta): "oi en esta fiesta hay puros weones' gay", y uno se acostumbra po'. Pero como que ahí, estar en este carrete que son como "héteros"y sentirte como la minoría ¿cachai? Como sentir que hay weás que no podí' hacer, como darte un beso o darte la mano, porque quizás a algún weón como que le puede dar rabia." (Silvain, 30 años, diseñador)

Tal como lo expone Silvain, no es extraño cuestionarse la performance sexual en espacios altamente heteronormados. Es interesante el hecho de que esta norma sea tácitamente compartida por las personas heterosexuales, pero de alguna forma más vívida por quienes se posicionan fuera de ella y por lo tanto enfrentan las represalias por no formar parte. Así, podrían enlistarse incontablemente los espacios públicos y privados en que prima punitivamente la heterosexualidad, como veremos más adelante. La importancia de esta norma, sin embargo, tal como lo retrata Silvain, es que regula las posibilidades de acción que cada persona tiene para con su cuerpo en cada espacio.

Sin embargo, en lo que refiere a las causas de la discriminación sobre la base de la heteronorma, podríamos cuestionar nuevamente el hecho que la heterosexualidad en las personas sea una fuerte mayoría en términos de frecuencia relativa, no conlleva directamente a la discriminación o exclusión de las minorías. Caleb, norteamericano fotógrafo y cineasta de 30 años, entrega desde su experiencia una posible respuesta comprensiva a la pregunta de quién y por qué fuera del mundo gay discrimina a los gays:

"Yo creo que también esas personas tampoco tienen poder, porque no sé, generalmente pasa como en sitio de construcción, o como... no sé, en situaciones donde la persona que lo está gritando está económicamente o de alguna forma menos privilegiada que yo. Están reclamando el poder donde lo tienen que es como en la heterosexualidad." (Caleb, 30 años, cineasta)

Caleb, en el mismo sentido, también se explica, por ejemplo, que el acoso callejero para él no tiene en sí el sentido de acosar, sino de demostrar 'hombría' frente a otros hombres - del mismo modo en que Segato propone entender las agresiones de género (2017). Lo rescatable de sus reflexiones para análisis posteriores es que logra conectar el acto discriminatorio con causas estructurales y, en este caso, entiende que el reclamo del poder dentro de la heteronorma es la compensación de la precariedad 
socioeconómica. Asimismo, continúa su reflexión comparando su país de origen (Estados Unidos) con Chile:

"Yo creo que si alguien es como un agresor potencial contra otra persona por cualquier motivo, incluso la homosexualidad o que sea una persona trans, la persona que es potencial, si esa persona tiene un poco mejor educación, como educación privada por ejemplo o un poco mejor seguridad social, no va a matar a una persona. Yo creo que esas personas serían menos propensas de cometer esas violencias si tuviera qué comer. Comparando Chile con Estados Unidos, Chile no es más homofóbico y Estados Unidos no es menos homofóbico como país, pero hay menos violencia en Estados Unidos, un poco menos, porque la gente tiene más recursos." (Caleb, 30 años, cineasta)

Tomando como cierta las hipótesis de Caleb sobre qué está en la base de la discriminación, se entra en la dificultad, por un lado, de que las causas que motivan la discriminación hacia homosexuales corresponden a condiciones estructurales que viven los sujetos en estas sociedades. Por lo mismo, pocos enfrentamientos cara a cara podrían efectivamente revertir una situación de discriminación, desmitificando prejuicios, por ejemplo, pues parte de las causas de ellos se juegan a un nivel estructural que va más allá de la interacción misma.

\section{¿Qué se demanda frente a esta situación?}

Es amplia la gama de demandas de los entrevistados relativa a su deseo de alterar su situación menoscabada. Éstas van desde la indiferencia frente a su orientación, matrimonio homosexual, respeto y seguridad en las calles, no discriminación, hasta el reconocimiento de otros tipos de dominaciones, en función de clases sociales, por ejemplo, cuestionamientos a los espacios heteronormados junto a sus instituciones que integrarían supuestamente a la población homosexual.

Por ejemplo, el matrimonio homosexual, apoyado por casi la totalidad de entrevistados, emergió como un tópico de discusión que nos sirve para exponer distintas demandas de parte de los entrevistados. Yván, quien se mueve en un contexto conservador, expresa una postura afín respecto al matrimonio:

"Me he criado en una familia y quiero tener mi familia, quiero tener educación, quiero estar tranquilo [...] Yo soy una persona católica y me gusta ir a misa. Algún día me gustaría casarme por la iglesia, pero ahorita no puede ser porque todavía no lo aceptan." (Yván, boliviano, 26 años, ingeniero comercial)

Yván tiene claro que desea casarse, no sólo por el registro civil, sino que también por la iglesia católica y es consciente de la contradicción que esto significa. Sin 
embargo, no quiere y no le importa ser identificado como gay y tampoco realiza ningún acto consciente de micro o macro política para eventualmente poder casarse en cualquier instancia. Otra variante de esta postura, más conformista y moderada, la representa Nicolás (31 años), ingeniero comercial que se desempeña en la industria de la construcción:

"Si hay matrimonio igualitario, bien, y si no, habrá que casarse por unión civil [...] Me parece un poco violento que todo sea ya, porque genera rechazo. Que, por ejemplo, de un año a otro sea matrimonio, después que tengan hijos, lo veo difícil de digerir para todo el mundo." (Nicolás, 31 años. ingeniero comercial)

Nicolás, de la misma manera que Yván, al hablar sobre sus aspiraciones de realización como personas homosexuales y la conquista de derechos sociales, tienden a quedarse en la exposición parcial y pasiva de su orientación. De hecho, Nicolás tuvo un espacio importante de hacer pública su orientación sexual hace unos años, cuando apareció como pareja de un animador de televisión en un importante evento nacional. A propósito, comenta que en aquella ocasión:

"Se habló sobre el tema. Se habló sobre el amor gay, sobre la relación gay, sobre lo que en el fondo era, se mostró que era una forma de amar [...] Obviamente lo que también mucha gente dice, que yo creo que también tienen harta razón, es que no sea tema, ¿cachai?, pero sí, fue súper positivo." (Nicolás, 31 años, ingeniero comercial)

Sobre todo, en citas como la anterior y en el discurso de Yván, resalta el carácter no problemático de sus posturas sobre un tema que constituye un problema para ellos y, al contrario, sus aspiraciones en tanto hombres gays son reivindicadas acríticamente en tanto derecho de personas del mismo sexo de amarse o de constituir familia.

En cambio, Caleb, al tematizar el matrimonio homosexual, se posiciona desde una vereda más crítica al pensar que éste se ha impuesto como el norte y fin de las luchas homosexuales:

"No es la manera correcta de buscar dignidad para nosotros. Como.... deberíamos tener derecho a caminar por la calle, de partida.... No sé, no a través de asimilarnos a como ritos culturales antiguos que hace la gente, que se supone que tenemos que hacer, como el matrimonio. Como "una persona normal en el Chile de hoy se casa, así que vamos a dejar que ustedes también se casen»." (Caleb, 30 años, cineasta)

Vemos de esta forma cómo personas pertenecientes a un mismo grupo delimitado, en este caso hombres gays de los sectores socioeconómicos altos del país, 
pueden tener posturas tan distintas sobre referentes comunes como el matrimonio homosexual. Se toma este ejemplo específico, pues dentro de los últimos años se ha impuesto efectivamente como uno de los horizontes normativos más próximos de la lucha homosexual en Chile y en el mundo. Esta divergencia de posturas podemos explicárnosla a causa de elementos específicos en el marco de sus procesos de individuación. Por tomar dos ejemplos, Yván reconoce y es consciente del fuerte componente conservador en el cual fue criado. Distinto es el caso de Caleb, quien explica su postura más crítica pues desde la escuela sufre discriminación y acoso a causa de su orientación sexual. Lo que, según él, si no hubiese estado presente en su vida, "probablemente sería una persona de mierda que no le importaran estas cosas". Es bajo esta perspectiva de individuación que es necesario "reconocer la singularización creciente de las trayectorias personales" (Araujo et al., 2010) para entender por qué situaciones similares maduran en respuestas distintas, sea la aceptación de las condiciones de discriminación o el vuelco hacia el compromiso político, y qué recursos son movilizados y permiten emerger una $u$ otra respuesta.

En cuanto a esto último, los recursos más comunes para hacer frente a la discriminación identificados en las entrevistas pudieron ser categorizados a grandes rasgos en, por un lado, recursos que son empleados de manera individual, como el humor, la confrontación al acto discriminatorio o el abandono y autoexclusión de espacios fuertemente heternormados, y, por otro, en recursos que implican de manera más directa a un/a tercero/a, como rodearse de amigas o personas que intermedien entre el medio y ellos mismos.

\section{Recursos individuales para hacer frente a la discriminación}

Entre los recursos individuales, uno de ellos es tomarse con humor las situaciones en que es remarcada la homosexualidad, por lo que no serían consideradas como discriminación. Comenta Yván (26 años, ingeniero comercial) sobre cómo vivió esto en su paso por una universidad prestigiosa de la quinta región: "obviamente siempre escuchas los típicos comentarios como «iay, ese maricón!» y ese tipo de cosas. Siempre hay algo. Pero de ahí cuando salí del clóset, mis amigos, si bien hacían esas bromas, nos reíamos el doble".

Sumado a esto los entrevistados dan cuenta que prestan mucha atención a la intención de la potencial acción discriminatoria en un sentido weberiano. Vicente (29 años, ingeniero comercial) define su postura: "oye si hay algo pa weviar [molestar], wevea en buena, si a mí me da lo mismo, si yo no soy un weón [hombre] traumado de “ioi no le digai maricones a esos weones!»". Como vemos en este caso, no obstante, al ser una interpretación del acto lo que prima, también Vicente se responsabiliza por los efectos de este acto. En este caso la comprensión actúa como una estrategia para fomentar su resiliencia social y no identificarse como víctima (Lamont et al. 2013). 
De manera similar, Silvain (30 años, diseñador) cuenta la ambigüedad de interpretar la acción de los otros: "como que wevean (molestan con humor) mucho, pero no es que sean homo-homofóbicos, ¿cachai? Es simplemente porque son muy buenos pal' weveo [...] O sea, no sé tampoco si cuenta como discriminación porque no es como con mala intención". Llama la atención sí, que, al momento de interpretar el acto, se cae también en la justificación de éste. Vemos además en estos casos citados que el humor, aparte de ser una vía para justificar los actos de discriminación, es un medio bastante utilizado para denigrar de manera disfrazada.

Otro tipo de recurso posibilitado por repertorios a los cuales los sujetos pueden acceder en términos de Lamont (2013), es replegarse hacia lo privado. Sobre esconder la homosexualidad con el fin de evitar ser discriminado en espacios de trabajo, Renato (30 años, psicólogo) comenta: "también creo que la sexualidad es algo muy propio y encuentro muy respetable que hayan personas que no lo quieran abrir porque en el fondo hay espacios de trabajo, por ejemplo, más en el mundo privado donde tú trabajas con otras cosas, ¿cachai? [...] No sé, rubros donde lo humano no es lo más relevante". Pues, entre hombres homosexuales es común hablar sobre si se dice que se es homosexual en el trabajo y cuáles son los riesgos asociados.

Es decir, en general es una por la otra: se puede decir que se es homosexual afrontando los potenciales riesgos de discriminación o esconderlo y no enfrentarse a ellos. Para varios de los entrevistados, es importante prepararse e incorporar recursos capitales o técnicos para desarmar cualquier posible intento de desvalidación. Éste es el tercero y más común recurso identificado entre sujetos que poseen ciertos niveles de capitales y recursos materiales: la ostentación. Uno de los ejemplos más claros sobre cómo son empleados los recursos lo expone Benjamín (40 años psicólogo y empresario):

"Yo he generado patrimonio que igual es grande en relación a mi edad y que tiene que ver con cómo yo... que de repente no lo comento mucho, pero las cosas que yo tengo en general no las tiene gente de mi edad, ¿cachai? Y que tiene que ver con estar preparado para distintos escenarios, ¿cachai? [...]Yo tengo un auto que es bien grande y siempre he tenido autos bien grandes y claro, es un auto súper masculino. [...] Además tengo un máster en la Adolfo Ibáñez, ¿te fijai?, sino que además aparte de recursos económicos tengo cinco propiedades ¿te fijai?, tengo como toda una cosa que finalmente no es tan habitual en alguien joven, entonces la gente me ve también como alguien que no es un perejil sin hojas y finalmente yo no soy un perejil sin hojas ¿cachai?" (Benjamín, psicólogo y empresario, 40 años)

De esta cita podemos analizar que no es sólo armarse de capitales para enfrentar el juicio externo, sino que es en primer lugar también para compensar la propia imagen menoscabada que se pueda tener. Estrategia que perfectamente puede ser utilizada para compensar otros tipos de discriminación. Similar a Benjamín, Nicolás 
(ingeniero comercial, 31 años) habla sobre cómo se refuerza a sí mismo laboralmente en función de lo que ha logrado: "si alguien no me quiere contratar, o considera que no puedo hacer un trabajo solo por el hecho de ser gay, ellos se lo pierden. Yo tengo hoy en día la suficiente credencial demostrable de cómo es mi trabajo, cómo soy yo como profesional, cómo yo me relaciono con las personas que he liderado...".

Podemos ver en todas estas citas que siempre subyace el juego de la identificación. ¿Me identifico yo con la figura del homosexual y en qué ocasiones y gracias a qué recursos? Y desde afuera, ¿me identifican con la figura del homosexual y qué implicancias tiene esto?

\section{Recursos relacionales para hacer frente a la discriminación}

Distinguir entre recursos individuales y relacionales importa en la medida en que los segundos implican fundamentalmente a un tercero en la acción y no dependen tanto exclusivamente de atributos personales, como credenciales, autos, justificación y humor, etc. Estos/as otros/as que pueden mediar en la manera de afrontar la discriminación pueden ser tanto otros terceros concretos, como amigos/as o familiares que ayudan a los sujetos implicados a enfrentar distintas pruebas de discriminación o representaciones de otros que ya cimentaron un discurso que legitima un repertorio de acción: desde una campaña política hasta un activista o artista famoso/a.

El primer recurso de este tipo distinguido por los entrevistados es la visibilidad que han tenido en los últimos años personas homosexuales en todos los ámbitos de la vida social. Yván (26 años, ingeniero comercial), quien es especialmente susceptible a estas imágenes por venir de un país más cerrado en cuanto a diversidad sexual, Bolivia, declara que ve "gente muy exitosa diciendo soy gay y punto. ¿Cachas? Que antes no se veía eso acá en Chile. Era súper conservador. Ahora ves hasta en propagandas y en todo y es algo muy normal". Cuando le pregunto si cree que estos íconos pueden ser modelos para todas las personas independiente de la fuerte marca de clase que en general implican, responde: "quizás tú no vas a tener los mismos recursos, pero no tienes por qué identificarte a los recursos, tienes que identificarte al significado de lo que representa esta pareja, son legalmente aceptados, ¿cachas?”.

Sobre el mismo tema, Nicolás (31 años, ingeniero comercial), quien ha experimentado a lo largo de su vida una movilidad socioeconómica ascendente, enfatiza en la diferencia de clase que se generan al momento de emerger cierto tipo de referentes homosexuales: "yo creo que mientras más organizaciones existan, mayor es el ruido que se va a generar, mayor va a ser el impacto que pueda haber, por tanto, es bueno que haya distintas formas de visibilidad. Sí siento que el tema de algunas 
organizaciones como que segmentó [...] se partió con el concepto de "gay lais»" estos casos el tercero implicado es una figura relativamente lejana pero que ofrece efectivamente un modelo legitimado a la sociedad con el cual estos sujetos pueden intentar identificarse. Más allá de qué tan universalizable sea, es reconocido como una alternativa a la histórica 'loca', 'maricueca', 'colipato' o ‘colisón'.

La familia en algunos casos puede actuar como un tercero que apoye los procesos de creación de un discurso sobre sí mismo o para salir del clóset frente a otros. En el primer caso, Renato (30 años, psicólogo), quien sufrió un vuelco hacia el activismo, enmarca este proceso facilitado por su tradición familiar: "yo creo que es algo valórico, como te digo, en mi familia eso tiene valor, ¿cachai? Creo que... supongo que también por mi propia historia de vida, mi familia siempre el tema de la injusticia, hay una sensibilidad especial por eso".

El segundo caso que emergió en las entrevistas sobre el rol de la familia es graficado por Benjamín (40 años, psicólogo laboral), quien comenta que fantaseaba con una salida del clóset conflictiva y que finalmente resultó ser lo contrario: "tuve como mucho apoyo y... además mis papás también se metieron en, fueron súper activos. Yo me acuerdo que ellos me dijeron, bueno, nosotros te vamos a ayudar también. "¿Cómo te podemos ayudar?» $Y$ yo les dije, «bueno, ayúdenme también contándole esto al resto de la familia». Y sentí que eso fue súper bueno, me fui sintiendo liberado porque no era sólo yo contándole a todo el resto, y también fue normalizar una situación y no exponerme a ciertas reacciones".

En el mismo sentido, Benjamín (40 años, psicólogo laboral) muestra la importancia de protegerse con personas. En su caso, es importante contratar a mujeres en los cargos directos en el trabajo, pues cuidarán la interacción con otros empleados. Cuenta que siendo gerente general de una consultora en que trabajaba, armó su equipo de confianza con dos ex compañeras de universidad, que lo resguardaban como "perros guardianes":

"Yo sentía que yo a estas dos personas que tenía como mis rottweilers como que me cuidaban ¿ya? De hecho el otro día andaba en un matrimonio en Antofagasta, el fin de semana antepasado, y una psicóloga que trabajó conmigo muchos años atrás me hizo el comentario, me dijo «pucha Renato, siempre me has caído tan bien y ahora te lo voy a comentar, ¿sabí qué? yo siempre sentí que estas dos personas que estaban... que eran estas dos tipas subgerentes no dejaban que nadie se acercara y yo me acuerdo una vez que fuimos a un happy hour y no sé quién propuso que hiciéramos algo después y tú dijiste 'iya, sí!', y yo

\footnotetext{
7 "Gay lais" es la variante homosexual de la expresión "lais". "Pelo lais" nace en la década del 2000 como una anglicanización informal del adjetivo "liso", que refiere a un estereotipo de personas, principalmente mujeres de clase alta en Chile que tienen el peso liso y castaño claro o rubio. Puede usarse como un sinónimo de "cuica/o".
} 
me acuerdo que ellas como que te agarraban la mano, algo así y pa' mí fue como súper patente de que ellas te ponían mucho freno»". (Benjamín, psicólogo, 40 años)

\section{Da la experiencia vivida al compromiso político}

Por último, llama principalmente nuestra atención aquí, en tanto condición necesaria para el activismo político, las experiencias de discriminación que permiten al sujeto comprometerse con la resistencia frente a la injusticia. Ejemplificaremos este punto con experiencias de los dos entrevistados que participan de organizaciones por la diversidad sexual.

La primera es de Renato, psicólogo de 30 años, quien cuenta que, al momento de realizar su práctica profesional en psicología clínica, su supervisora estaba "siempre como haciéndome preguntas que tenían ver con la sexualidad de los otros, como asumiendo que yo estaba conflictuado con ellos porque no quería hacer visible que yo era gay, siendo que en verdad ese no era mi tema, yo sabía que era gay y sabía que me gustaban los hombres". Agrega que esta situación puso en peligro su titulación efectiva, por lo que decidió movilizarse:

"Entonces me sentí súper cuestionado, me sentí súper vulnerable eh... Empezamos a tener una disputa de poder porque siempre las intervenciones que yo hacía ella me las invalidaba, y no sólo ella, había todo un equipo que en el fondo me cuestionaban las cosas que yo hacía. Lo que derivó en que me evaluaran mal y si yo no aprobaba mi práctica, me quedaba la cagá' [un desastre]. Entonces apelé, dejé 'la casa de putas' y al final igual salí airoso, pero tuve que dar una pelea como heavy [difícil] en contra Goliat. Entonces siento que en ese momento me sentí también tan eh... desvalido, que también fue un motor para decir «weón [hey], esta weá [situación]... no puede seguir pasando». Entonces eso sumado a otras cosas, creo que me llevaron un poco a decir, iya... quiero ser activista en esta weá [causa]!” (Renato, 30 años, psicólogo)

Otra experiencia de discriminación que condujo hacia una transformación de disposición hacia el compromiso político lo retrata muy claramente Camilo, anestesista y académico de 62 años. En sus palabras: "a mí me tocó ser discriminado por una universidad de los Opus dei en una oportunidad de manera muy pública y fea y desde entonces yo me sentí comprometido a defender la causa, a promover la causa". Camilo narra que en un momento de su carrera se le pide que desarrollara un programa de postgrado, el cual presenta: "es discutido, aplaudido y aprobado". No obstante, al momento de elegir al jefe de este nuevo programa, eligen a otra persona. Cuando Camilo preguntó por qué, le respondieron que a causa de su orientación sexual. 
Señalaron "que ellos querían que yo siguiera trabajando, pero que por mi nombre no querían que tuviera un cargo de connotación pública por mi orientación sexual. Que yo podía seguir trabajando, pero en un segundo plano, en un lugar discreto".

Al igual que Renato, Camilo comenta que emocionalmente esto fue muy duro para él: "yo lloré largamente, lo pasé muy muy mal, me fui algunos días a la playa, yo lloraba por lo que me había pasado". Da cuenta, sin embargo, que pasado el "golpe", se dio cuenta que esa experiencia personal podría ser de utilidad pública. Camilo aprovechó que ese mismo año había sido reconocido a nivel nacional para asociar su fama en el país al hecho de ser gay, lo que constituye un cambio claro y radical respecto a cómo estaba conjugando su vida personal y laboral hasta ese momento, de manera más privada.

Tras esta experiencia de discriminación personal y laboral, Camilo cuenta que puso este episodio en conocimiento de personajes públicos a nivel nacional: "le dije a todos que yo había sido discriminado por mi orientación sexual... No dije que era gay, pero dije que había sido discriminado por mi orientación sexual para que todos lo entendieran y asociaran a esta persona que había sido distinguida a nivel nacional con un personaje gay. Quise hacer esa asociación con fin activista". Posterior a eso, Camilo se integró a una fundación que trabaja sobre estas temáticas.

Se puede identificar de manera muy clara el componente emocional en ambas experiencias de discriminación. En el caso de Renato, podríamos deducir que fue necesario que él se viera a sí mismo como desvalido para movilizarse por esta situación. En otro momento de la entrevista con Renato, al preguntarle por la situación degradada de los homosexuales, respondió asociando directamente sin mediación sobre la situación de una persona con discapacidad. En el caso de Camilo, el ímpetu que lo lleva a denunciar su experiencia de discriminación parte del daño sufrido por él, que luego se vuelva hacia un compromiso para que a otros no les pase lo mismo.

Retomando la interrogante planteada sobre distintas disposiciones frente a una situación común, podemos preguntar ahora desde la perspectiva de la experiencia de discriminación, ¿cuál es la especificidad de ésta que conduce en unos casos a un proceso sensible-reflexivo que vuelve intolerable la situación y en otros no? Aunque no sea posible homogeneizar las distintas trayectorias de vida para todos los hombres homosexuales, aun siendo una comunidad relativamente pequeña, podemos señalar que no sólo está el vuelco al activismo para hacer frente a la discriminación, sino también otros capitales, económico, culturales y sociales que logran suavizar la experiencia misma y, por lo tanto, debilitar el potencial político.

\section{Conclusiones}

Los hallazgos muestran que hombres homosexuales de los sectores socioeconómicos más altos en Chile se sirven de su posición de clase privilegiada para comprender y aceptar su deseo homosexual y que realizan operaciones 
conscientemente clasistas para compensar la discriminación homosexual. Dicho de otra forma, la estrategia consiste en que sólo una vez que se arman de capitales, efectivamente se sienten seguros para "sacar del clóset" su orientación sexual. De manera que independiente de su propio proceso de reconocimiento, la aceptación no pasa en último punto por ellos y, en consecuencia, su integración social permanece parcial. Por lo mismo, los sujetos entrevistados dan cuenta que efectivamente en momentos específicos de sus vidas deben reprimirse o tergiversar la presentación de su identidad para aplacar los potenciales actos discriminatorios.

Teniendo en consideración la situación de integración parcial que dejan entrever los entrevistados a causa de su orientación sexual, para la reproducción de su propia posición de clase, estos sujetos están perfectamente enterados sobre cómo la clase social tienen un componente de sexo-género que a ellos les puede jugar en contra. No obstante, difícilmente se encontró en su discurso una aproximación crítica hacia las clases sociales, incluso si ellos mismos son conscientes sobre cómo pueden ser perjudicados por la misma consubstancialidad.

Además, el desarrollo de una economía gay celebrada en gran parte por los sujetos entrevistados (ostentación, empleos, nichos de mercado, barrios gentrificados) permite mejorar la calidad de vida de ellos en tanto homosexuales de una forma sin precedente, permitiéndoles emerger, en parte, de los submundos sexuales marginales y miserables. Lo problemático de este capitalismo rosa es que no altera, sino que refuerza la ideología sexual que sustenta el sistema jerárquico de valor sexual. La homosexualidad grosso modo no deja de ser menos aberrante y la heterosexualidad no pierde su carácter de norma, sino que estas diferencias quedan obscurecidas por el eje de la clase que se impone sobre la sexualidad simulando espacios de aceptación (precaria) para los homosexuales homonormados. En efecto, esta política de la individualidad de la mano de las empresas y el imperialismo ${ }^{8}$ desarticula a su vez las condiciones de una movilización que transmita la crueldad de la persecución sexual o que cuestione una cultura del privilegio y la punición.

\section{Bibliografía}

Allan, Víctor (2015): Segmentación socioeconómica por ingreso y tamaño del hogar a partir de la Encuesta CASEN 2013. Criteria Research.

\footnotetext{
'El'Pinkwashing' puede ser entendido como estrategias de blanqueamiento de políticas u orientaciones fascistas o represivas de gobiernos y Estados que se abren a las diversidades sexuales mostrándose pro-Derechos Humanos. El caso más controversial del uso político de homosexuales y diversidad sexual es Israel como país que promociona la expresión de identidades diversas y la no discriminación: Pau López Clavel (2015): "Tres debates sobre la homonormativización de las identidades gay y lesbiana".
} 
Revista Punto Género № 12. Diciembre de 2019

ISSN 0719-0417 / 73 - 100

Andréu Abela, J. (2001): Técnicas de Análisis de Contenido: Una revisión actualizada. Centro de Estudios Andaluces.

Araujo, K., Martuccelli, D. (2010): La individuación y el trabajo de los individuos.Educação e Pesquisa, São Paulo, v.36, n. especial, p. 077-091, 2010.

Arrivo, Nicholas M. (s.d.): "Selling Sexuality: A Critical Genealogy of Homosexuality and Capital".

Barrientos, J., Cárdenas, M. (2013): Homofobia y Calidad de Vida de Gay y Lesbianas: Una Mirada Psicosocial. Revista PSYKHE Vol. 22, N¹, 3-14.

Barrientos, J., Cárdenas, M. \& Gómez, F. (2014): Características sociodemográficas, bienestar subjetivo y homofobia en una muestra de hombres gay en tres ciudades chilenas. Cad. Saúde Pública, Rio de Janeiro, 30(6):1259-1269.

Baudrillard, Jean (1974): "Función-signo y lógica de clase" y "Hacia una crítica de la economía política del signo”, en Crítica de la economía política del signo, Siglo XXI.

CASEN (2013): Evolución y distribución del ingreso de los hogares (2006-2013). Ministerio de Desarrollo Social, Gobierno de Chile.

(2015): "Encuesta de Caracterización Socioeconómica Nacional'. Ministerio de Desarrollo Social, Gobierno de Chile.

CEPAL (1992): Cambios en la estratificación social y estilos de desarrollo. Algunas hipótesis de trabajo.

De Baére, F., Zanello, V., Romero, A. C. (2015): Los insultos entre homosexuales: ¿la transgresión de la heteronormatividad o la duplicación de valores de género? Rev. bioét. (Impr.). 2015; 23 (3): 627-37.

Drydakis, Nick. (2009): "Sexual orientation discrimination in the labour market". Labour Economics 16.

Encuesta Nacional UDP, 2005-2015 (2015): ICSO Instituto de Investigación en Ciencias Sociales UDP. Facultad de Ciencias Sociales e Historia.

Feagin, J. \& Eckberg, D. (1980): Discrimination: Motivation, Action, Effects, and Context. Ann. Rev. Social. 1980. 6:1-20. 
Fraser, N. (2008): La justicia social en la era de la política de la identidad: Redistribución, reconocimiento y participación. Revista de Trabajo • Año 4 • Número 6.

Herek, G. M. (2000): The Psychology of Sexual Prejudice. Current Directions in Psychological Science 9, 19-22.

(2004): Beyond "Homophobia": Thinking About Sexual Prejudice and Stigma in the Twenty-First Century. Sexuality Research \& Social Policy. Journal of NSRC.

Lamont, M., Welburn, J. S., \& Fleming, C. M. (2013): Responses to discrimination and social resilience under neoliberalism: The United States compared. In P. A. Hall \& M. Lamont (Eds.), Social resilience in the neoliberal era (pp. 129-157). New York, NY, US: Cambridge University Press.

Madrid, Sebastián (2016): La formación de masculinidades hegemónicas en la clase dominante. Sexualidad, Salud y Sociedad - Revista Latinoamericana.

Martinic V., Sergio (2006): El estudio de las representaciones y el Análisis Estructural de Discurso. Metodologías de investigación social. Introducción a los oficios. Editor Manuel Canales Cerón. Lom ediciones.

Movilh (2013): Primera Encuesta Nacional. DiversidadSexual, Derechos Humanos y Ley Contra la Discriminación.

(2018): "XVI Informe Anual de Derechos Humanos de la Diversidad Sexual y de Género en Chile. Hechos 2017".

Myrdal, G. (1964): “An American Dilemma”. Vol. 1. NY: McGraw-Hill.

ONUSIDA (2012): Índice Compuesto de Estigma y Discriminación hacia hombres homosexuales, otros HSH y mujeres transgénero en Chile. Síntesis de Estudio.

Reisigl, M., Wodak, R. (2008): The Discourse-Historical Approach (DHA).

Sandfort, T., Melendez, R. \& Diaz, R. (2007): Gender Nonconformity, Homophobia, and Mental Distress in Latino Gay and Bisexual Men. Journal of Sex Research. Vol. 44, №2, 181.189.

Segato, R. (2017, 2 Septiembre): "Una falla del pensamiento feminista es creer que la violencia de género es un problema de hombres y mujeres". El Ciudadano: https://www.elciudadano.com/entrevistas/rita-segato-una-falla-del-pensamiento-feminista- 
Revista Punto Género № 12. Diciembre de 2019

ISSN 0719-0417 / 73 - 100

es-creer-que-la-violencia-de-genero-es-un-problema-de-hombres-y-mujeres/09/02/

Torche, Florencia, Wormald, Guillermo (2004): Estratificación y movilidad social en Chile: entre la adscripción y el logro. CEPAL, División de Desarrollo Social.

Weinberg, G. (1972): Society and Healthy Homosexual. St. Martin's, New York. 